\title{
Extraction of ERP Selection Criteria using Critical Decisions Analysis
}

\author{
Motaki Noureddine, Kamach Oualid \\ National School of Applied Sciences of Tangier \\ Tangier, Morocco
}

\begin{abstract}
Companies use ERP systems to automate business processes in order to increase productivity, reduce costs, and meet customer requirements. ERP selection for an enterprise is a decision-making project that is both risky and expensive, a wrong selection of this system or project partners can lead to the failure of the ERP implementation project. In this paper, we combined the theoretical findings of ERP selection issue with expert's practical recommendations to determine the critical decisions that need to be made in the pre-implementation phase. Then we presented a methodology to determine ERP selection criteria based on the critical decisions analysis. A part of this work was performed within a company that has just launched an ERP implementation project.
\end{abstract}

Keywords-ERP selection; criteria; critical decisions; implementation; information system

\section{INTRODUCTION}

Companies need to increase productivity, decrease total costs, reduce stock, meet the customers' requirements, maximize return on investment (ROI) and reduce lead times. To overcome these challenges and improve efficiency to be competitive, companies often use ERP systems.

An enterprise resource planning system (ERP) is a software package composed of business applications (modules) that automate core corporate activities and the set of business tasks with the aim of better support enterprise's top managers' decision making.

ERP systems are regarded as a way of becoming and maintaining competitiveness, with the use of ERP, different components of information system coming from different parts of the organization can be unified and stored in a centralized database. Indeed, main corporate activities such as inventory control, purchase, production planning, sales, manufacturing, supply chain management, human resources and finance can be integrated and automated through a several modules included in ERP system and meet most of company's requirements.

Many improvements can be achieved by successfully implementing an ERP: this system offers many benefits for enterprise such as improved supply chain management, instant access to reliable information, elimination of multiple data entries and redundant operations, time saving and costs reduction. In addition, productivity is achieved through ERP systems by automating, integrating and standardizing business processes.

ERP system's adoption considered as one of the most critical investment projects due to the high cost, complexity and adaptation risks. Companies are spending huge budgets and hiring work teams for a considerable period of time using both of its internal resources and external consulting to implement an ERP system.

Given the diversity of companies' business processes, strategies, goals, services and business sectors, ERP systems in market cannot fully meet all special business requirements of companies and satisfy completely their needs. Many companies implement their ERP software without given enough importance to the selection phase and without understanding requirements that must be included in chosen ERP package. A wrong selection may lead to unsuccessful ERP implementation project that can affect the performance of the company.

From this aspect, to make ERP implementation project successful, managers must initiate an ERP selection project whose objective is to choose suitable ERP software that most closely suits its requirements. Moreover, Selecting an ERP system is an extremely risky, high cost and difficult decisionmaking problem for managers. It's a whole process which requires more than interviewing a few vendors: it is considered as the most critical success factor for ERP implementation.

For ERP selection problem, researchers proposed various methods that differ from each other based on their complexity and tools used. A part of these methods are based on mathematical optimization, scoring and ranking techniques while others use multi-criteria decision analysis approaches. All ERP selection methods use selection criteria that can evaluate ERP alternatives.

During the ERP selection process, the criteria list must be determined; however, there is no unique way to classify these criteria. There are little works that has proposed a comprehensive methodology to extract and determine the criteria for selecting an ERP in an industrial context [15], [16], [24].

In this paper, we will present a methodology for extract the selection criteria based on the critical decisions that must be made by steering team. We will start by determining the list of critical decisions according to the relevant literature on ERP selection in one hand, and the practical recommendations of the ERP experts we interviewed in other hand. Then we will describe our methodology which generates selection criteria from each critical decision.

\section{LITERATURE REVIEW}

In the recent literature there are various studies proposing different techniques and methods to provide a solution to ERP selection problem, several evaluation methods have been 
proposed, such as scoring, ranking, mathematical optimization and multi-criteria decision analysis [8].

Numerous studies proposed multi-criteria decision-making methods (MCDM) to prioritize alternatives and calculate the relative efficiencies of ERP solutions [1], [2], [3], [7], [9]. A part of these studies are successfully combined more than one multi-criteria decision-making methods (hybrid methodology) [2], [5], [6], [7], [21], while other studies have focused on identifying success factors in ERP selection process [10], [11], [20].

The review of the state of the art on ERP selection Methods revealed the following methods:

AHP (Analytic Hierarchy Process) [1], [13], [16], [17], [23], ANP (Analytic Network Process) [5], [14], [15], [23], PROMETHEE [2], [5], SHERPA (Systematic Help ERP Acquisition), FL (Fuzzy Logic) [3], [12], [15], [17], [18], PM (Priority Matrix), TOPSIS (Technique for Order Preference by Similarity to Ideal Solution) [24], [25], SMART [4].

In previous years, researchers conducted theoretical and empirical studies to identify and analyze the selection criteria for a suitable ERP system [22].

Based on data from 19 Canadian organizations that have adopted the ERP system or are evaluating the adoption of an ERP system, Kumar, Kumar, and Maheshwari presented the most used ERP selection criteria. According to this study, some of these criteria include Functionality of the system (79\%), Systems reliability (64\%), Fit with organization systems (64\%), Available business best practices in the system (50\%), Cross module integration (50\%), System using latest technology (43\%), Vendor reputation (43\%) [24].

Little research has addressed the issue of criteria identification in ERP selection context: (Chun-Chin Wei et al.) proposed a method to systematically identify the appropriate selection criteria, through the construction of ERP selection objectives.

The method proposed is based on enterprise strategic objective and presented in several steps [16]:

1) Define enterprise strategic objectives.

2) Define ERP system scope by project team.

3) Drive the ultimate goals from the strategic objectives

4) Structure the objectives by distinguishing fundamentalobjectives from means-objectives in the objective development process.

5) Establish the hierarchy of ERP system fundamentalobjectives, using top-down decomposition method or bottomup synthesis method.

6) Create a means-objective from the fundamentalobjectives and determine linkages among them.

7) Extract the attributes (criteria) used for ERP evaluation: quantitative and qualitative attributes that satisfy the strategies and goals of the company should be involved.

In this study, the authors explained step by step how to construct a specific objective structure relating to the company's strategies and how to extract the proper criteria for evaluating the fulfillment of company's requirements.

Baki and Çakar, presented results from a study on ERP package selection criteria in 55 Turkish manufacturing companies from variety of industries, they proposed a criteria list that include fit with parent/allied organization systems, better fit with organizational structure, functionality, system reliability, technical criteria, compatibility with other systems, cost, vision, ease of customization, service and support, market position of the vendor, domain knowledge of vendor, references of the vendor, methodology of the software and consultancy, cross module integration, implementation time [26].

To determine a set of ERP selection criteria Ayağ and Özdemi analyzed a set of companies that have already implemented an ERP system. They observed how companies defined the selection criteria for the adoption of their ERP, According to the authors, the ERP selection criteria can be classified into three determinants that have relationships with each other: competitive advantage, productivity, profitability. Under the three determinants, seven dimensions are listed: system cost, vendor support, flexibility, functionality, reliability, ease of use and technology advance. These dimensions play an important role for each determinant and affect each other (Fig. 1). Ultimately, 22 criteria are determined. All the criteria of a dimension are linked and influence each other positively or negatively [15].

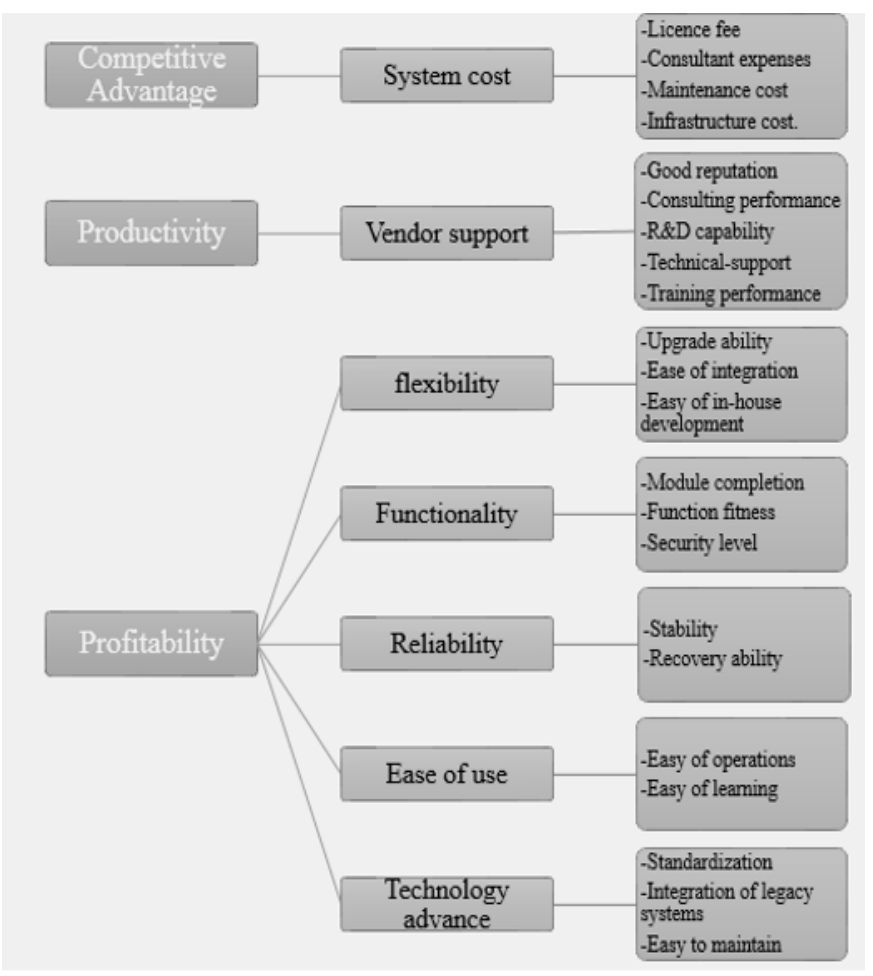

Fig. 1. Determinants, dimensions and criteria according to Ayağ and Özdemi.

Based on the research related to ERP selection topic, it is clear that the diversity of selection criteria complicates their classification into standard groups. 
Frequently, ERP selection criteria are defined according to researchers specialty or based on the results found in literature, these criteria are divided in general into several categories which differs from a research work to another, and as we mentioned above, there are little works that has proposed a comprehensive methodology to extract and determine the criteria for selecting an ERP in an industrial context.

In a large number of the works carried out to find a solution to ERP selection issue, researchers used a list of the criteria to evaluate ERP systems through different methods (AHP, ANP, TOPSIS, and fuzzy Logic) but without explaining how they have obtained these criteria.

\section{RESEARCH METHODOLOGY}

The objective of this paper is to present critical decisions for selecting ERP system and to propose a simple and practical method that uses these critical decisions to determine the selection criteria list. Through this method, steering team can extract and evaluate principal criteria for ERP selection by making decisions that will take into account company constraints and requirements.

Our proposal can be summarized by the following research questions:

- Are there techniques for defining and evaluating selection criteria?

- What are the decisions to make before starting the ERP selection process?

- What is the impact of the critical decisions on ERP selection criteria?

- How can we extract the selection criteria from the decisions made by the steering team?

To perform this work, the relevant literature on ERP selection was analyzed, summarized and complemented by information available in cases studies and surveys, we raised up the most popular ERP selection methods and criteria. Furthermore, we reviewed several ERP selection processes to determine their strengths and limitations.

Moreover, theoretical findings related to the ERP selection were combined with ERP practical recommendations in order to derive insights.

Indeed, we conducted a series of meeting and interviews with ERP Consultants, projects managers, various department heads, who already participated in ERP implementation projects.

Accordingly, we were able, through these interviews, to extract the best practices followed, and identify different problems encountered in the ERP selection phase to improve the proposed method.

In fact, a part of this work was performed within a company that has just launched an ERP implementation project. This enterprise is located in the north of Morocco, and is considered as a member of a holding company that already uses a SAP ERP.

\section{SELECTION PROCESS}

The purpose of the ERP selection process is to choose the appropriate ERP system that can meet the enterprise requirements. This process involves several stages starting from the constitution of the selection team until signing the contract with the vendor [19].

Different models available to represent the selection process, we present below the most common stages in these selection process models:

Step 1: Constitution of the selection team: The first step in the selection process is to form the selection team that include IT experts and key members from each department with suitable competencies and knowledge. This team must collect the needs of each department and identify the characteristics of the ERP system, as they have to establish a short list of vendors...

Step 2: Determination of the ERP required functionalities: The objective of this step is to determine functional specifications related to the new information system (based on ERP), including functionalities, constraints, and management rules associated to the company functions. These technical and functional specifications will be used to evaluate each alternative ERP solution.

Step 3: Definition of the evaluation criteria used to select the suitable ERP provider: ERP selection criteria will be determined by the selection team in collaboration with the steering team based on the company constraints, the consultants' advices and the critical decisions (purpose of our contribution) made in the pre-implementation phase.

Step 4: Definition of the ERP shortlist: In order to create an ERP short list, selection team conducts market analysis and identifies potential suppliers. Indeed, this team takes care of the collection of all available information about ERP systems, and identifies those who are specific to the industrial activity of the company, and to find out the ERP systems employed by similar companies (benchmarking).

Step 5: Evaluation of the ERP according to the selection criteria: In this step, weights associated to the selection criteria will be determined after a consultation session performed by the selection team. Thereafter, alternative ERP systems will be evaluated using multi-criteria decision methods such as AHP, ANP, and TOPSIS. These methods can be applied in order to deal with the ambiguities involved during the evaluation of ERP alternatives.

Step 6: Selection of the suitable ERP: After evaluating each ERP product on the short list, the company may start by inviting the chosen ERP vendors in order to do a Demonstration of the Product and then later, they can start the Negotiations before signing the contracts.

\section{CRITERIA LIST}

We propose in this section an original vision of criteria, based on the stakeholders of ERP implementation project: vendor, integrator (consultants), client and partners (Fig. 2): 
- Vendor: The enterprise that has developed the ERP system, it provides technical support for the ERP. For some criteria, we will confuse vendor and ERP product.

- Integrator: Represent functional and technical consultants and experts involved in various business processes, it ensures the accompaniment of the client in the ERP implementation project

- Client: Enterprise that will use the ERP (project owner); it generally initiates the ERP selection process.

- Partners: Customers, suppliers and group's members in case the client is part of a holding company. In the selection process, partners' information systems should be taking into account.

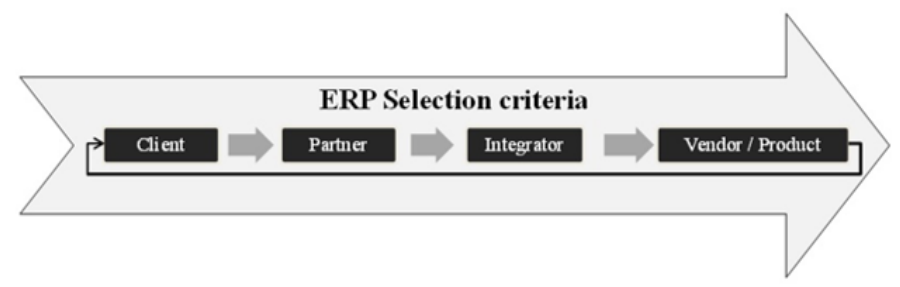

Fig. 2. Stakeholders of ERP implementation project.

Table I summarizes the selection criteria of the ERPs according to the stakeholders.

This structuring allows organizing selection criteria according to the chronological order of ERP selection process. Indeed, criteria related to the Client (the company that will use the ERP) and its partners, are the most critical and must be evaluated first. These criteria represent the results of a deep analysis of the company's business needs and must reflect its objectives and strategy.

The ERP product and vendor criteria focus on the evaluation of functional and technical aspect of the ERP and the quality of services offered by vendor, as well as its market position. The fourth element of this structure is the integrator criteria that assess the quality of experienced integrators for a given ERP, its related implementation methods and the overall implementation costs.

For our proposed method, this structuring will be used as a reference to determine selection criteria list that better matches the company's requirements. Thus, we can see that the criteria list generated according to our method will be a subset of the reference list.

\section{CRITICAL DECISIONS}

Several critical decisions (Table II) must be taken by selection team before starting the selection process; these decisions should allow the determination of the ERP selection criteria adopted for the assessment of each alternative ERP (Fig. 3). Indeed, for each decision element, selection team can choose from several options. Subsequently, for each chosen option, one or more ERP selection criteria will be generated (Fig. 5).
TABLE I. ERP SELECTION CRITERIA ACCORDING TO THE STAKEHOLDERS

\begin{tabular}{|c|c|}
\hline Stakeholder & Criteria \\
\hline Vendor/Product & $\begin{array}{ll} & \text { Vendor market position. (C1) } \\
\text { - } & \text { References. (C2) } \\
\text { - } & \text { Financial position. (C3) } \\
\text { - } & \text { Reputation in the field (C4) } \\
\text { - } & \text { Technical support (C5) } \\
\text { - } & \text { Training support (C6) } \\
\text { - } & \text { Service \& support cost (C7) } \\
\text { - } & \text { Functionality. (C9) } \\
\text { - } & \text { Implementation of Desired Business Processes. } \\
\text { - } & \text { Short Implementation Time. (C11) } \\
\text { - } & \text { Ergonomic Software. (C12) } \\
\text { - } & \text { The provision of best practices. (C13) } \\
\text { - } & \text { Latest trends in the IT industry. (C14) } \\
\text { - } & \text { Modules independency. (C15) } \\
& \text { The ability to integrate different platforms and } \\
\text { - } & \text { Syste. (C16) } \\
\text { - } & \text { Flexibility in adjusting demands according to } \\
& \text { business requirements. (C18) } \\
\text { - } & \text { Ease of use / implementation. (C19) } \\
\end{array}$ \\
\hline Client & $\begin{array}{ll}- & \text { Enterprise size. (C20) } \\
- & \text { Activity area. (C21) } \\
- & \text { Desired Business Processes. (C22) } \\
- & \text { Enterprise budget. (C23) } \\
- & \text { Technical Infrastructure. (C24) } \\
\end{array}$ \\
\hline Integrator & 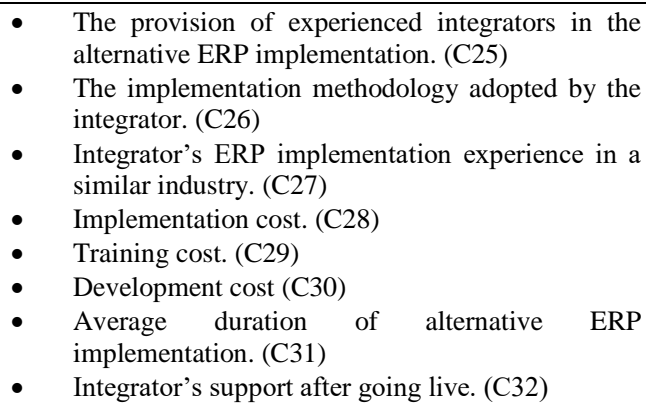 \\
\hline Partners & $\begin{array}{l}\text { - } \\
\text { (CRP systems used by customers and/or suppliers. } \\
\text { - Consultant's suggestions. (C34) } \\
\text { - The level of use of the ERP by competing } \\
\text { enterprises or enterprises whose business sector is } \\
\text { the same. (C35) } \\
\text { - Customer and Supplier Needs. (C36) }\end{array}$ \\
\hline
\end{tabular}

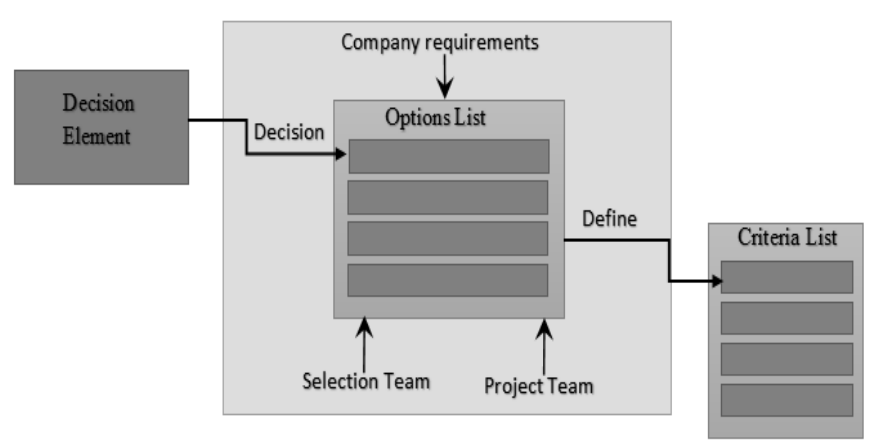

Fig. 3. General model: extraction of ERP selection criteria. 
TABLE II. ERP SELECTION CRITICAL DECISIONS

\begin{tabular}{|l|l|}
\hline Critical Decision & Code \\
\hline ERP Type & CD1 \\
\hline Deployment Type & CD2 \\
\hline Target Processes & CD3 \\
\hline ERP Adaptation Level & CD4 \\
\hline Existing SI situation & CD5 \\
\hline Existing Provider situation & CD6 \\
\hline Partners recommendations & CD7 \\
\hline Technical Implementation type & CD8 \\
\hline Implementation team involved & CD9 \\
\hline ERP Project Budget & CD10 \\
\hline ERP Project Duration & CD11 \\
\hline
\end{tabular}

\section{A. Critical Decision 1: ERP Type}

There is a wide variety of ERP systems designed to help SMEs and large companies to manage their information systems, these ERPs differ from each other according to various aspects such as the business sector, management best practices, target company size, integrated process complexity, and functional coverage of each proposed module.

The first critical decision is to determine the type of ERP that will be implemented: The steering committee must choose between an ERP for SMEs and an ERP for large companies. This decision makes it possible to define two major criteria: the type of ERP that must fit with the company size, and the ERP functional coverage according to the company activity area.

\section{B. Critical Decision 2: Deployment Type}

Firstly, the project team must define the strategic vision of the enterprise towards the ERP implementation project, and determine the parts of the company (sites, departments) concerned by this project. They will answer the basic questions regarding the aspect of the deployment: Will the ERP deployment be performed by module, by process, by site? Or it is a full deployment that concerns all functional parts of the enterprise.

This decision allows to determine specific ERP modules that will be used, and to specify if these modules must be independent or not, and finally, to determine the ERP implementation method that corresponds to the deployment type adopted.

\section{Critical Decision 3: Target Processes}

What are the organizational processes that will be managed by the ERP? What functionalities would be needed to manage each process? Through these questions, the project team can describe in details a list of processes that the enterprise wants to manage, and then determine ERP modules that will be used to achieve this objective.

The project team should determine all the business processes that will be subject to automation through the ERP: a preliminary study of existing user environment and various departments' needs must take place to be able to define the company's requirements, extract the requested functionalities, and then formulate the ERP functional criteria.

This Decision element will be used to establish multiple selection criteria used during the selection process. Moreover, it makes it possible to fill in associated criteria such as ERP compatibility with the enterprise processes, and inclusion of management best practices.

\section{Critical Decision 4: ERP Adaptation Level}

The project team will determine the functional implementation strategy by specifying whether the ERP must adapt to the company's processes through specific developments, or it is the company that has to adapt to the ERP by investing in business process reengineering (BPR).

The determination of functional implementation strategy of the ERP will have a direct impact on the adopted criteria: if we choose a strategy based on the adaptation of the ERP then the criteria adopted will be the development cost and the flexibility of the ERP, while in case we chose to adapt the company's business processes, two criteria will be adopted: functionality and inclusion of management best practices (Fig. 4).

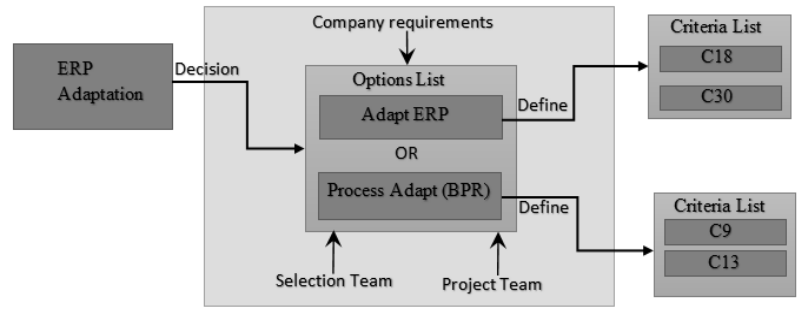

Fig. 4. Criteria extraction example according to CD4.

\section{E. Critical Decision 5: Existing SI situation}

Generally, a company already uses several application packages to manage data from different departments. Each application provides several functions, and uses its own database, but does not necessarily communicate with other applications.

Based on the needs specified in a previous step, the steering team must decide about which specific applications will be replaced by the ERP modules, and which ones need to be interfaced with the ERP.

If the steering committee decides to replace all the application packages with the ERP then this decision makes it possible to choose the appropriate criteria from functional coverage and integrity (C9), and implementation of desired business processes (C10), whereas in the case where the ERP must communicate with other applications, the adopted criterion will be the ability to integrate different platforms and data (C16).

\section{F. Critical Decision 6: Existing Provider situation}

Some companies already have previous experience with an existing ERP vendor, it consists in providing and implementing ERP product to manage one or more business processes in the company sites and subsidiaries. The success or failure of this previous experience can have an impact on the enterprise decision regarding the acceptance of this vendor for a new ERP implementation project.

Indeed, if this vendor receives highly favorable reviews, then its ERP product will be privileged compared to other ERP alternatives, otherwise this ERP will be eliminated from the alternatives shortlist automatically. 


\section{G. Critical Decision 7: Partners recommendations}

Each company has different type of partners (suppliers, customers, subsidiaries, group members in the case of a holding company), the steering team can discuss if the ERP adopted by the business partners of the enterprise will be taken into consideration in the selection process.

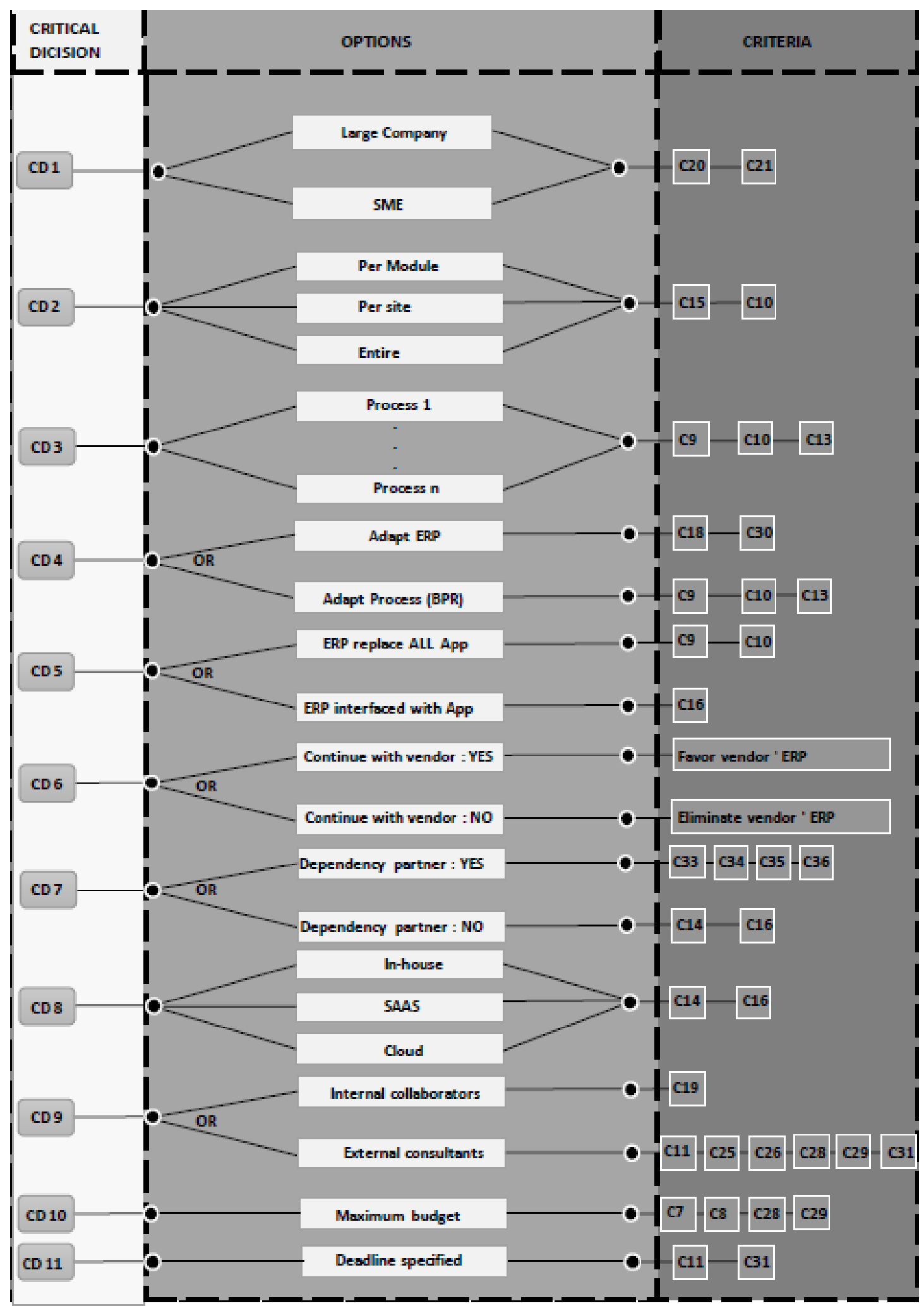

Fig. 5. Criteria generated according to the critical decisions. 
This decision has a critical effect on the ERP selection Process, especially if partners require that a particular ERP must be used, in this case the ERP adopted by the partner will be favored compared to other alternatives. In the opposite case, the selected ERP must be able to communicate with the Information System of the partners and support the exchange with different systems and data, hence the need to adopt the C14 and C16 criteria.

\section{H. Critical Decision 8: Technical Implementation Type}

Before launching the selection process, the technical implementation type of the ERP must be defined; several types of installations can be used: in-house installation, outsourced installation based on datacenters, software as a service (SAAS), and ERP installation based on Cloud.

In the case of an internal installation: does the company keep the same IT strategy: operating system, DBMS, network architecture? Or will it be aligned with the requirements of the chosen ERP?

The suitable ERP must comply with all the technical requirements of the company, and particularly the installation method (Fig. 6).

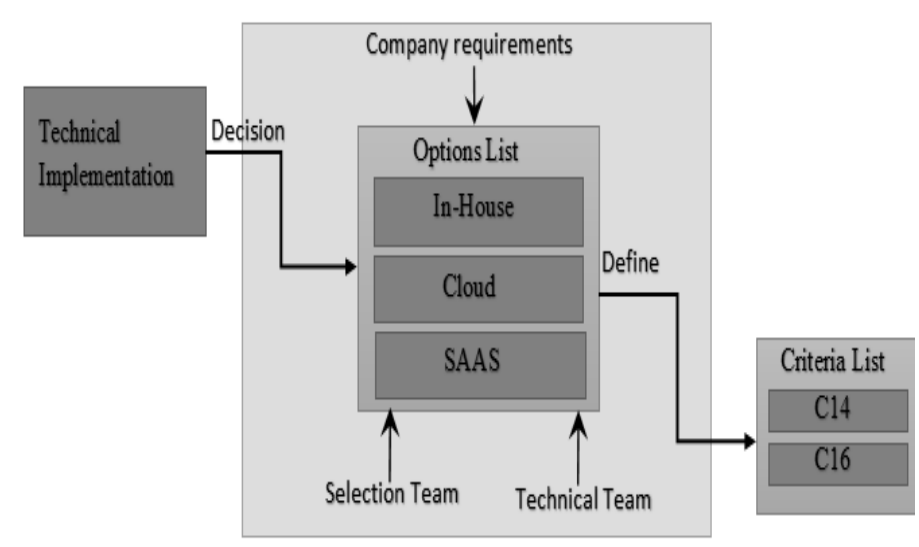

Fig. 6. Criteria extraction example according to CD8.

\section{Critical Decision 9: Implementation team involved}

During an ERP project, the integrator can support the company in the different phases of ERP implementation: starting from the requirements specification to the Go Live phase through the collaboration with a set of technical and functional consultants that have a good experience in this type of projects.

Some companies prefer that the ERP implementation should be performed entirely by their internal teams. In this case, ERP ease of use and implementation method simplicity are two essential criteria in the ERP evaluation Process. In the opposite case, the company can delegate the implementation of the ERP to an experienced integrator, therefore six ERP selection criteria will be defined (Fig. 5). These criteria evaluate implementation methodology of each alternative ERP and the quality of associated integrators.

\section{J. Critical Decision 10/11: ERP Project Budget and Duration}

The selection team must be aware of the maximum budget set by the company for ERP project as well as the planned date to start the Go Live phase. These two elements (budget and deadline) make it possible to define criteria evaluating methodology and duration of the ERP implementation on the one hand, and all the explicit and hidden costs of the ERP implementation project on the other hand.

The following table (Table III) summarizes all the questions that must be answered in the decision-making phase (critical decisions).

TABLE III. CRITICAL DECISIONS QUESTIONS

\begin{tabular}{|c|c|}
\hline $\begin{array}{l}\text { Decision } \\
\text { element }\end{array}$ & Questions \\
\hline CD1 & $\begin{array}{l}\text { What is the type of ERP to adopt? An ERP for SMEs } \\
\text { or an ERP dedicated to large companies? }\end{array}$ \\
\hline $\mathrm{CD} 2$ & What kind of deployment will be used? \\
\hline CD3 & $\begin{array}{l}\text { What are the organizational processes that will be } \\
\text { managed by the ERP? What functionalities would be } \\
\text { needed to manage each process? }\end{array}$ \\
\hline CD4 & $\begin{array}{l}\text { What level of adaptation will be considered? } \\
\text { What is the implementation strategy that should be } \\
\text { adopted? }\end{array}$ \\
\hline CD5 & $\begin{array}{l}\text { What will be the new situation of the business } \\
\text { applications of the company? } \\
\text { Will all these applications be replaced by ERP? } \\
\text { Are there any applications that need to be interfaced } \\
\text { with ERP? }\end{array}$ \\
\hline CD6 & $\begin{array}{l}\text { In case of a previous experience with an existing } \\
\text { ERP vendor, will this ERP provider be taken into } \\
\text { consideration in the selection process? }\end{array}$ \\
\hline CD7 & $\begin{array}{l}\text { The fact of "ERP adopted by enterprise partners?" } \\
\text { will be taken into consideration in the selection } \\
\text { process? } \\
\text { The fact of "ERP recommended by consultants or } \\
\text { partners?" will be taken into consideration in the } \\
\text { selection process? }\end{array}$ \\
\hline CD8 & $\begin{array}{l}\text { What kind of technical implementation will be } \\
\text { adopted by the company? }\end{array}$ \\
\hline CD9 & $\begin{array}{l}\text { Will the ERP implementation project be performed } \\
\text { by an internal team or by an external integrator? }\end{array}$ \\
\hline CD10 & $\begin{array}{l}\text { What is the budget allocated by the company for this } \\
\text { ERP project? }\end{array}$ \\
\hline CD11 & $\begin{array}{l}\text { What is the desired duration for the implementation } \\
\text { of the ERP solution? }\end{array}$ \\
\hline
\end{tabular}

\section{DISCUSSION AND CONCLUSION}

Usually the ERP selection has a profound impact on the success or failure of the implementation project, and should be planned very carefully by the selection team.

The strategic vision of the enterprise towards the ERP implementation project should be clear and unique for all the people involved in this project. Moreover, the requested functionalities and the business processes that will be managed by the ERP must be clearly identified before starting the selection process. 
ERP system should be flexible and customizable and generally encompasses best practices in a given industry. the steering committee must determine adaptation level of the ERP that will be adopted, If changes to the company business process are required, the means involved and the change's cost must be clearly identified and communicated to financial decision maker, Else if changes to the ERP itself will be needed, then in this case, the cost of customizing the ERP through specific developments must be determined. The ERP selection team must understand that the decision to customize the ERP or change the business process will have an impact on the criteria that will be used to evaluate the ERP.

In addition, the selection team must identify the type of technical implementation that will be used to install the ERP then determine the new situation of legacy system: identify the applications that will be replaced by ERP, and those that must be interfaced with this new system.

Several charges and expenses can be seen during an ERP project: license cost, integration cost, maintenance cost, training cost, and data migration cost. The budget allocated to the implementation project is a key factor for the ERP selection, the estimated cost of implementation of each alternative ERP must be calculated carefully and compared against the budget allocated by the company for the ERP project.

The complexity of the implementation methodology of a given ERP has a direct impact on the project duration, the selection team must take into account this estimated duration to evaluate each alternative ERP.

Selection team and steering committee must understand that the selection criteria adopted for the ERP evaluation depends on the critical decisions made before starting the selection process.

In this work we have determined a list of critical decisions that must be made by the selection team and the steering committee, these decisions concern all the functional, technical and organizational aspects encountered in an ERP implementation project and which has a direct impact on the selection process.

The proposed methodology was partially developed in a company that just started the ERP selection project, we were able to take advantage of the opinions of the ERP consultants and the business process managers on the problems encountered and the critical decisions that must be made to succeed the project Selection.

On the theoretical side, a part of our methodology has been based on the analysis of the literature on ERP selection and the results obtained in case studies and surveys.

We have raised the most popular ERP selection criteria and then structured them according to the stakeholders of an ERP project in order to respect the chronological order of the ERP implementation project evolution.

In addition, after presenting the critical decisions for the selection of the ERP, we proposed various possible options for each decision, and thus determine the criteria generated according to the chosen option.
This methodology has the advantage of being practical and simple to use, moreover it takes into account the technical, functional and organizational constraints of the company and its specific needs. All the criteria generated reflects the company's requirements and will be determined from an indepth discussion by the selection and steering teams. This will ensure that the ERP system selected through these criteria will be most suited to the company needs.

\section{REFERENCES}

[1] Maria Manuela Cruz-Cunha, "ERP Selection using an AHP-based Decision Support System", IRMJ journal, vol. 29, Issue 4, 2016.

[2] Sandarbh Shukla, Mishra, Rajeev Jain, Yadav, "An integrated decision making approach for ERP system selection using SWARA and PROMETHEE method", International Journal of Intelligent Enterprise, vol. 3, Issue 2, 2016.

[3] Burak Efe, "An integrated fuzzy multi criteria group decision making approach for ERP system selection", Applied Soft Computing, vol. 38, pp. 106-117, January 2016.

[4] Moutaz Haddara, "ERP Selection: The Smart Way" Procedia Technology, Vol. 16, pp. 394-403, 2014.

[5] Huseyin Selcuk Kilic, Selim Zaim and Dursun Delen, "Selecting "The Best" ERP system for SMEs using a combination of ANP and PROMETHEE methods", , Expert Systems with Applications, Vol. 42, Issue 5, pp. 2343-2352, 1 April 2015.

[6] Kilic, Zaim, and Delen, "Development of a hybrid methodology for ERP system selection: The case of Turkish Airlines", Decision Support Systems Journal, vol. 66, pp. 82-92, October 2014.

[7] Gürbüz, Alptekin and Isıklar Alptekin, "A hybrid MCDM methodology for ERP selection problem with interacting criteria", Decision Support Systems Journal, vol. 54, Issue 1, pp. 206-214, December 2012.

[8] Lin, Chen, Ting, "An ERP model for supplier selection in electronics industry", Expert Systems with Applications Journal, vol. 38, Issue 3, pp. 1760-1765, March 2011.

[9] Karsak, Özogul, "An integrated decision making approach for ERP system selection”, Expert Systems with Applications, vol. 36, Issue 1, pp. 660-667, January 2009.

[10] Malhotra and Temponi, "Critical decisions for ERP integration: Small business issues", International Journal of Information Management, vol. 30, Issue 1, pp. 28-37, February 2010.

[11] Hakim and Hakim, "A practical model on controlling the ERP implementation risks", Information Systems Journal, vol. 35, Issue 2, pp. 204-214, April 2010.

[12] Sen, C. G., Baraçlı, H., Sen, S., \& Baslıgil, H, "An integrated decision support system dealing with qualitative and quantitative objectives for enterprise software selection". Expert Systems with Applications, vol. 36, pp. 5272-5283, 2009.

[13] Ünal and Güner, "Selection of ERP suppliers using AHP tools in the clothing industry", International Journal of Clothing Science and Technology, vol. 21 Issue: 4, 2009.

[14] Perçin, "Using the ANP approach in selecting and benchmarking ERP systems", Benchmarking: An International Journal, vol. 15 Issue: 5, pp. 630-649, 2008.

[15] Ayag and Özdemir, "An intelligent approach to ERP software selection through fuzzy ANP", International Journal of Production Research, vol. 45, pp. 2169-2194, Issue 10, 2007.

[16] Wei, Chien and Wang, "An AHP-based approach to ERP system selection", International Journal of Production Economics, vol. 96, Issue 1, 18 April 2005, pp. 47-62, 2005.

[17] Özdağoğlu and al, "Comparison of AHP and Fuzzy AHP for the MultiCriteria Decision Making Processes with Linguistic Evaluations”, 2007.

[18] Yu-Rong Zeng, Lin Wang \& Xian-Hao Xu, "An integrated model to select an ERP system for Chinese small- and medium-sized enterprise under uncertainty", Technological and Economic Development of Economy, pp. 38-58, 2 November 2015.

[19] Igor Rivera and María del Rosario Pérez Salazar, "Guía de Selección de Erp En Las Pequeñas Y Medianas Empresas Mexicanas”, 2013. 
[20] Wen-Hsien Tsai, Pei-Ling Lee, Yu-Shan Shen and Hsiu-Ling Lin , "A comprehensive study of the relationship between entrerprise resource planning selection criteria and enterprise resource planning success", 2013.

[21] Huseyin Selcuk Kilic, Selim Zaim and Dursun Delen ,"Selecting "The Best " ERP system for SMEs using a combination of ANP and PRPMETHEE methods", vol. 42, Issue 5, pp. 2343-2352, 1 April 2015.

[22] Moutaz Haddara and Ondrej Zach, "ERP Systems in SMEs: A Literature Review", 2011.

[23] Cristina Lópeza, Alessio Ishizakab, "GAHPSort: A new group multicriteria decision method for sorting a large number of the cloud based ERP solutions", Computers in Industry, pp. 12-24, 2017.
[24] V. Kumar , B Maheshwari \& U. Kumar, "Enterprise resource planning systems adoption process: A survey of Canadian organizations", International Journal of Production Research, vol. 40, Issue 3, pp. 509$523,2010$.

[25] Rekha Gupta and S. Kazim Naqvi, "A Framework for Applying CSFs to ERP Software Selection: An Extension of Fuzzy TOPSIS Approach",International Journal of Intelligent Information Technologies (IJIIT), vol. 13, Issue $2,2017$.

[26] Baki, B., \& Çakar, K., "Determining the ERP package-selecting criteria: The case of Turkish manufacturing companies", Business Process Management Journal, vol 11, Issue 1, pp. 75-86, 2005 